\title{
Article \\ Case of Study in Online Course of Computer Engineering during COVID-19 Pandemic
}

\author{
Paula Lamo *(1), Mikel Perales (i) and Luis de-la-Fuente-Valentín (i)
}

Citation: Lamo, P.; Perales, M.; de-la-Fuente-Valentín, L. Case of Study in Online Course of Computer Engineering during COVID-19 Pandemic. Electronics 2022, 11, 578. https://doi.org/10.3390/ electronics 11040578

Academic Editors: Mohammed Amin Almaiah,

Ahmad Al-Khasawneh,

Sébastien Jacques and

Omar Almomani

Received: 28 December 2021

Accepted: 12 February 2022

Published: 14 February 2022

Publisher's Note: MDPI stays neutral with regard to jurisdictional claims in published maps and institutional affiliations.

Copyright: (c) 2022 by the authors. Licensee MDPI, Basel, Switzerland. This article is an open access article distributed under the terms and conditions of the Creative Commons Attribution (CC BY) license (https:// creativecommons.org/licenses/by/ $4.0 /)$.
Escuela Superior de Ingeniería y Tecnología, Universidad Internacional de La Rioja, 26006 Logroño, Spain; mikel.perales@unir.net (M.P.); luis.delafuente@unir.net (L.d.-l.-F.-V.)

* Correspondence: paula.lamo@unir.net; Tel.: +34-9-4121-0211

Abstract: Practical activities and laboratories, where the students handle hardware devices, are an important part of the curriculum in STEAM degrees. In face-to-face learning, the students go to a specific classroom where the hardware is available. However, laboratories are one of the challenges of distance education, due to the impossibility of the students attending classes at a certain place. This is especially relevant since the COVID-19 pandemic, thanks to the increase of students enrolled in distance education. Different approaches to tackle this problem have been adopted, ranging from mixed models where lectures are online but physical attendance to laboratories is required to purely virtual models where virtual worlds or augmented reality have been used to simulate the real hardware. This paper presents the case of study of a flexible laboratory for the use of Arduino in a Computer Technology course with 153 students, geographically distributed in Spain and Latin America. The goal of the case study is to study the impact of such a flexible laboratory in the course, based on four fundamental parameters: student access to the online lectures, participation in the course and marks obtained, and satisfaction surveys. The results show that students have increased their marks by $28.8 \%$ and their class attendance by $247.18 \%$, doing more elaborate and complex work than in previous courses. Therefore, it is considered that they have satisfactorily integrated the knowledge acquired during the subject, and the projects with Arduino in Computer Technology have an impact on the flexibility and personalization of the education, motivate students and increase its educational productivity and effect on the quality of education, influencing the learning experience.

Keywords: online teaching; flexibility; Computer Technology; project-based learning; Arduino; video games; Computer Engineering; undergraduates; pandemic situation; COVID-19; case of study; student profile

\section{Introduction}

Online teaching offers a wide range of possibilities to students in engineering and technical degrees, such as the little or no mobility required and the flexibility of schedules [1]. These advantages are highly valued and sought after by students in recent times due to the COVID-19 pandemic [2], but also by those students who cannot attend a face-to-face center for work reasons, personal burdens, or ubication. This has produced a significant increase in the number of enrollments made in degrees that offer this methodology, especially during the world pandemic [3,4].

Online education faces a number of challenges that may not affect face-to-face settings, or are not even present in that case. For example, in face-to-face universities, there is no need to deploy and administer any Learning Management System (LMS) that supports the process. Some universities foster a blended model where the LMS serves as additional support, but some teachers use it and some others do not and this fact does not affect the satisfaction of the students. However, in online education, the LMS is the most important means of communication among students and teaching staff and, for this reason, the 
LMS is a critical infrastructure. As a result, the maintenance of LMS often requires an important investment.

The factors that affect the success of online education have been the subject of research in different studies. A conceptual framework [5] identifies four main aspects: website quality factors, technological factors, management support, and awareness. Thus, the educational institution needs to deploy such an infrastructure that supports the educational process with reliability at the time that offers good design, access speed, and content quality. Awareness is also identified as an important factor in online education, as the different players (students, teachers) need to know how others react to the different interactions, and they also need to know whether (or not) they are correctly using the platform.

Cultural factors are also identified as a relevant adoption aspect [6,7]. Online education is more prone to be accepted where the potential students have received enough information and communication technology (ICT) education. Another related factor is trust: students are reluctant to accept online education where they cannot trust the reliability of the different actions, ranging from the basic submission of exercises to the teacher, to the electronic payment of the different fees.

In engineering, one of the major concerns of this methodology is the difficulty of introducing the knowledge and practical skills obtained in face-to-face laboratories, where equipment and materials are handled, without losing quality in the teaching-learning process. For this reason, the disciplines closest to technology and engineering incorporate laboratory practice as a fundamental part of student training. Active learning through online laboratories is the protagonist for distance education students, who can access them without leaving their homes. This flexibility allows students who combine their studies with a job to adapt their learning times to a full work schedule. This essentially simple model presents a real challenge when students are scattered around the world. To solve this problem, some institutions have opted for blended models [8-10], in which the students attend the lectures remotely but must attend a minimum number of face-to-face laboratory sessions where these skills are practiced. However, this system does not offer a completely online modality and forces the student to physically appear in a specific place, losing the advantages of flexibility and zero mobility. Other universities have chosen to send work kits to their students with all the necessary material and tools, so that each one can work with it safely at home, guided by the teacher [11]. The drawback of this proposal is the logistical challenge posed by sending these kits to educational centers when students are not geographically located in the same delimited area. To eliminate these problems, some centers have opted to establish remote laboratories, such as LabsLand [12,13], which have real equipment installed in different parts of the world and students can access them remotely to interact with the laboratory components. However, access to these laboratories can be expensive and even limited in time and in the resources that students can access. Furthermore, remote laboratories' integration in the e-learning environment can be a great challenge considering the different backgrounds of the main actors [14,15]. However, in recent years, online interaction has improved, becoming more effective and more affordable. Therefore, thanks to this development, the formation of distributed workgroups only requires selecting the appropriate tools and processes, instead of making technological leaps [16]. So virtual labs are no longer a novelty for technical university studies. It is common to find subjects with laboratory practices that develop a virtual experiment $[17,18]$. These types of tools, normally integrated into a collaborative environment, are part of the evolution of online training. They are presented as a cost-effective implementation for schools and universities to organize high-quality laboratory work in any discipline where the student has to experiment [19]. Developments in modern laboratories have allowed the inclusion of gamification, virtual worlds, and augmented reality in virtual laboratories, taking the user experience to a new dimension [20]. In this context, there are also important studies on the virtual laboratory experience in the field of electronics, such as in [21], where some preliminary results are presented that demonstrate the potential to provide a flexible 
evaluation, saving time, improving experimental skills, and increasing student confidence. Based on the above, the gap between real labs and virtual labs is closer to closing.

Other relevant aspects are the heterogeneous profiles of the students in the same class and how to capture their interest. The conditions derived from the pandemic have pushed different profiles to study a new degree motivated by the benefits of the online methodology [22]. They justify their choice with health security, family conciliation, or improving their family situation [9]. This has led to a significant increase in online students and a change in the access profile, which is inevitably associated with a change in their context, productivity, and motivation, as explained in [23]. One of the main problems these students may face is that they are isolated [24] and may be more likely to not pay attention to the teacher, procrastinate, or multitask while the class is in progress. Also, they may not be attracted to repetitive and non-personalized materials, such as self-assessment tests [25]. In this sense, the teacher must make a special effort to explain real practical examples to the students that give meaning to the contents and motivate them, considering the cultural, multinational, and generational diversity that may exist in these groups [23]. Such real-world examples have been effective in attracting their attention and encouraging them to continue with their studies, as well as increasing the evaluation of the teachers.

In Computer Engineering, a subject that is especially sensitive to all the problems mentioned above is Computer Technology, where students must develop and handle physical hardware in a practical way and as close as possible to the reality of the industry in which students will be developed as professionals in the future. The contents of the course focus on digital circuits, the representation of data at the machine level, the organization at the assembler level, and the study of the organization and structure of the components of a computer [26]. Traditionally, in the lab sessions of this subject, the teachers show the components of a computer and its assembly from equipment. On the contrary, in the online model, a student loses the ability to use this equipment, since the only equipment available to them is their own and they do not want to manipulate it for fear of damaging it. However, there are a wide variety of systems that can be considered a computer. This definition includes many types of devices, from single-chip microprocessors, which cost a few euros, to supercomputers that can cost up to millions of euros [26]. This diversity influences the cost, size, performance, and applications. Some examples are smartphones, game consoles, laptops, smart TVs, Field Programmable Gate Arrays (FPGAs), digital signal processors (DSPs), or Arduino boards. It is precisely these examples that are the most motivating for students [27].

Considering all of the above, this manuscript presents an exhaustive analysis of the new student profile and a teaching case of study based on project-based learning (PBL) [28] and is aimed at knowing the structure, organization, operation, and interconnection of computers in a Degree in Computer Engineering using Arduino. The purpose of the practice is threefold: firstly, it seeks to help students of the Degree in Computer Engineering at the Universidad Internacional de La Rioja strengthen their knowledge of the basic principles of digital logic, digital systems, data representation at the machine level, memory organization and its structure and inputs/outputs (I/O) of a computer using Arduino. Secondly, it is about providing students with real practical examples that give meaning to the contents and motivate them, attracting their attention and encouraging them to continue with their studies in a flexible way. Finally, it is about developing a flexible and personalized framework for online students with very heterogeneous profiles. Therefore, the development of thorough project-based learning that can be carried out in two different ways, through simulation with Autodesk ${ }^{\circledR}$ TinkerCad ${ }^{\circledR}$ or using Arduino, is proposed. Each option will have a different proposal and, to avoid plagiarism, the student must show a high degree of originality in their solution and make a public presentation. Also, the objective of this work includes the study of the engagement that students achieve with the presented proposal. This study is based on three hypotheses: the projects with Arduino in Computer Technology (i) have an impact on flexibility and personalization of the education, (ii) motivate students and increase their educational productivity, and (iii) effect on the 
quality of education, influencing the learning experience. To this end, the document has been divided as follows. Section 2 describes the context and motivation of the proposal. Section 3 shows the developed project. In Sections 4 and 5, the proposal is discussed and its limitations are mentioned and, finally, the conclusions and future works are presented.

\section{Context and Motivation}

The global COVID-19 pandemic has changed the lives and habits of millions of people around the world [9]. These changes have also been reflected in the profile of students who were enrolled in Computer Engineering in Universidad Internacional de La Rioja, as reflected in the initial survey to its students in the first week of the academic year. The results of this survey are used in the rest of this section to describe the course context. Figure 1 shows the percentage of students by age range who enrolled in Computer Engineering in the last three academic years. During the 2019/20 course, the ages of the students were similarly distributed in all ranges, although those over 45 years old were the predominant profile. As a result of the pandemic situation, this trend radically changed in 2020/21, when $40.84 \%$ of students with 18-24 years old were registered and those over 45 years old went from being the majority group to only $12.6 \%$. However, the trend changed again during the last year, although the predominant groups continue to be students aged 18-29 (46.06\%). As a result, the average age of students has also decreased from 34.16 years $(2019 / 20)$ to 31.85 years (today).

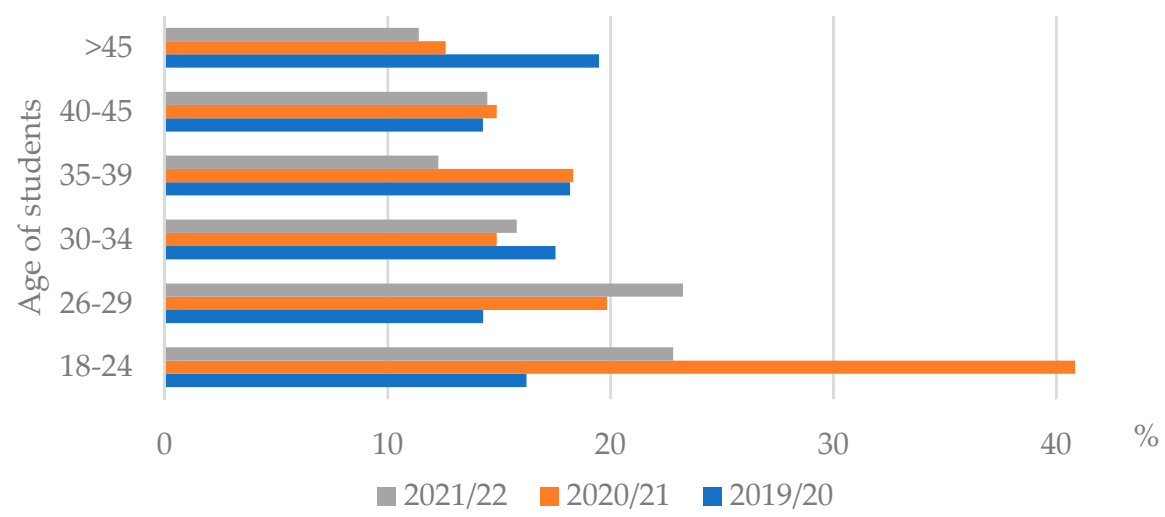

Figure 1. Distribution of students by age ranges in Computer Engineering.

This change has affected the age of the students and also their gender. In Figure 2, the percentage distribution of males and females in this study is shown, where the percentage of women has increased from $14.94 \%$, during the 2019/20 course, to $20.18 \%$ in 2021/22.

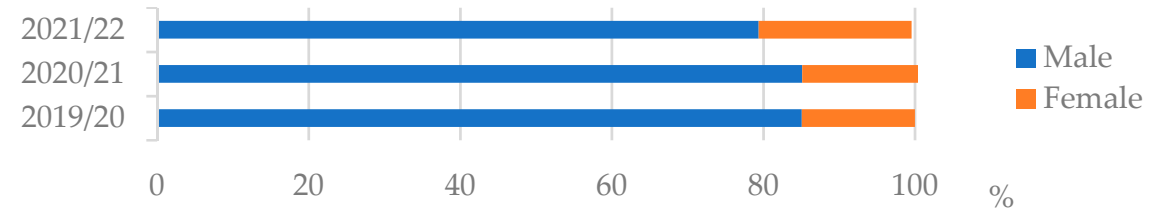

Figure 2. Distribution of students by gender in Computer Engineering.

The students enrolled in Computer Engineering in 2019 came mainly from Spain (78.9\%). Latinos represented 19.57\% and the rest of Europeans (non-Spanish), 1.51\% (Figure 3a). During the pandemic, the number of students increased over the previous year by $26.2 \%$ in 2020 and $17.89 \%$ in 2021 . However, although the number of students from all countries increased, the increase in Spanish students was significantly higher. This meant that $84 \%$ of students were Spanish in $2020 / 21$, compared to $14.08 \%$ of Latinos and $1.19 \%$ of other Europeans. In 2021/22, the percentages are 82.99, 15.38, and 1.61\%, respectively. Spanish students, for their part, have diverse origins, as can be seen in Figure $3 \mathrm{~b}$. Although they mostly come from the center of the country, there are many students from the north of 
the country (Cantabria and Asturias), the northwest (La Rioja and Navarra), and the east (Murcia and Valencia). This dispersion of students throughout the world poses a complex scenario where the profile of students is highly varied in terms of their origin and culture.

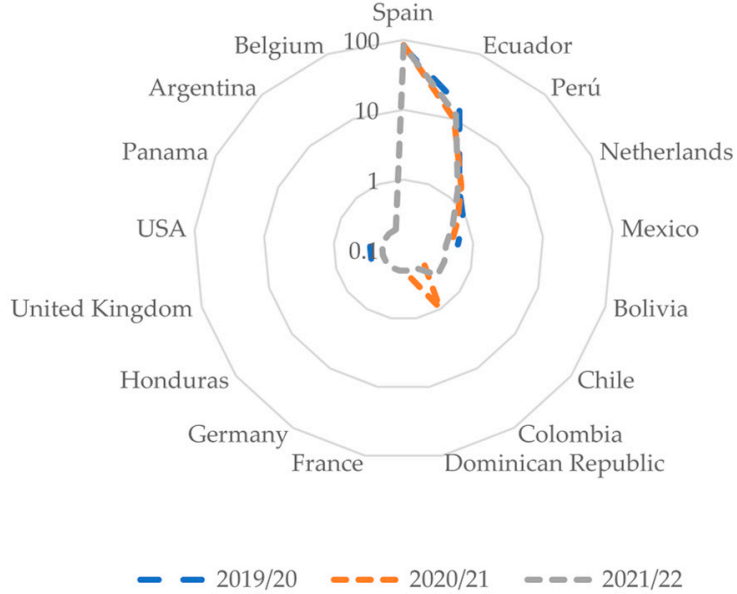

(a)

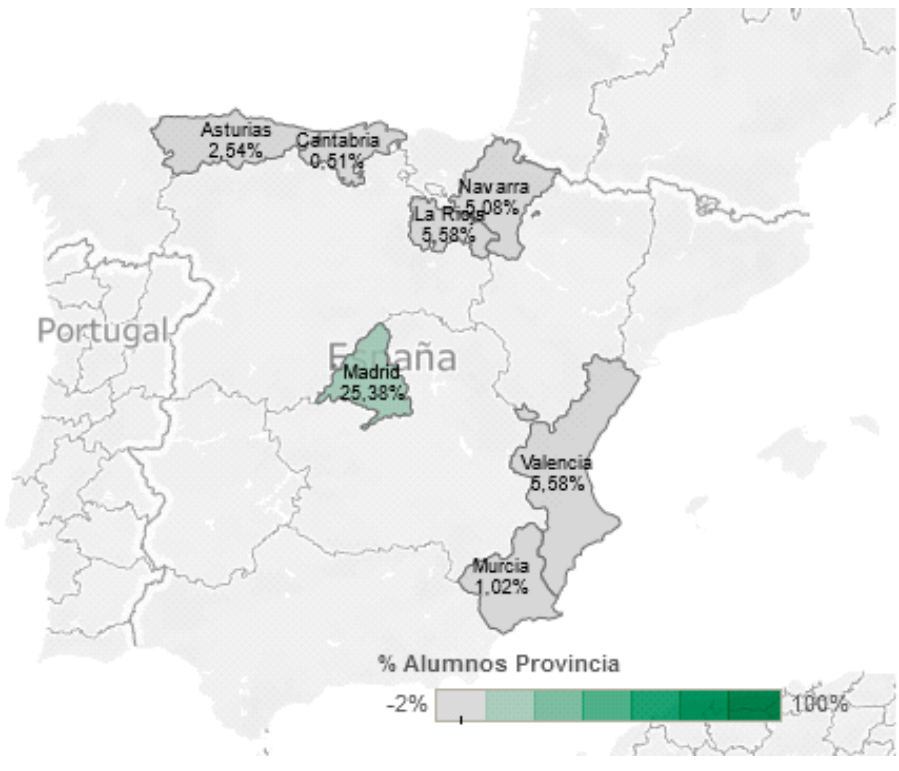

(b)

Figure 3. Distribution of students by location in Computer Engineering. (a) Percentage distribution during the last 3 years and (b) percentage distribution of the location of Spanish students.

According to their professional situation, the profiles of the students are diverse. In Figure 4, an overview of the professional profile of Computer Engineering students at the Universidad Internacional de La Rioja is presented. Figure 4a shows how the majority profile of students prior to the pandemic corresponded to employed workers in private companies (56\%). However, although this is the majority occupation of students, since the COVID-19 pandemic, public workers have significantly decreased and the profiles of students, unemployed, entrepreneurs, and others, such as those people who are part of companies with open government files to regulate employment, have increased. The dedication of these students to their work has also changed. In 2019, full-time workers were the majority (95\%). A year later, this percentage decreased to $69 \%$ in favor of students who do not work while studying or have part-time jobs. Finally, in Figure 4c, the professional sectors of the students are shown. In 2019, students were predominantly from commerce, financial services, and industry and energy sectors. However, after the pandemic, the majority of the profiles correspond to people who work in auxiliary services and industry and energy.

On the other hand, the motivations of the students have not changed with the pandemic, and the majority claim to choose this study because it is a highly demanded degree in their labor sector (60-65\%); they want to achieve better working conditions (35-48\%); and it is a vocational qualification, which they always wanted to study (27\%).

Regarding the level of studies, the casuistry has not varied significantly, and the variety is wide. For this reason, and for the sake of clarity, only the results obtained in this course (2021/2022) are shown in Figure 5. Most of the students have no previous university training (79\%), although 8\% have a master's degree and 1\%, Ph.D. (Figure 5a). However, the high number of students who indicate having received some type of training in the last year (48\%) is highlighted compared to those who have not studied anything in 1-5 years $(27 \%)$ and those who have not have done anything for more than 5 years $(15 \%)$, in Figure $5 b$. 


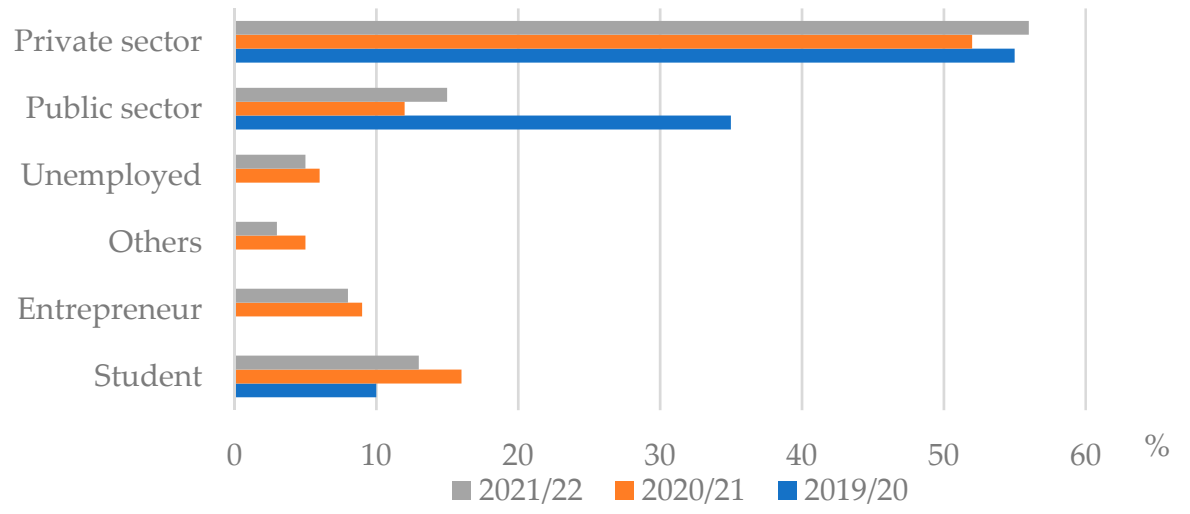

(a)

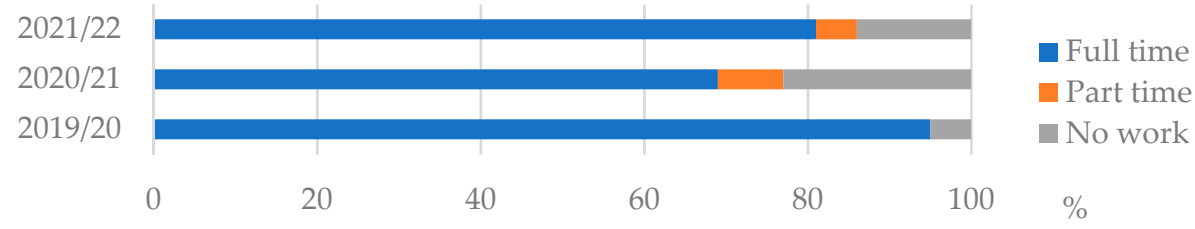

(b)

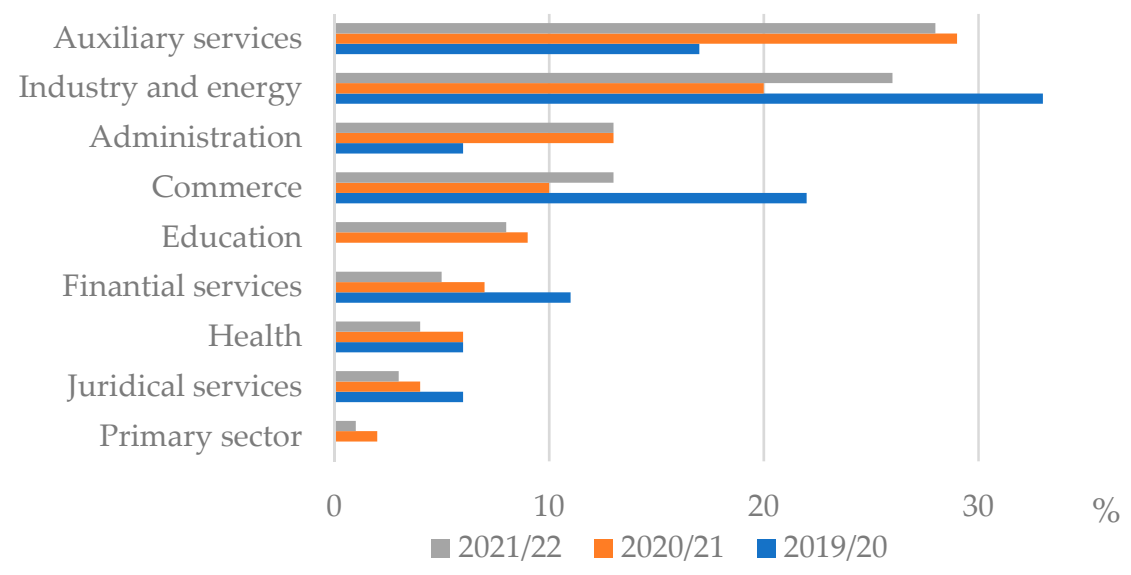

(c)

Figure 4. Distribution of students by professional sector in Computer Engineering. (a) Labor situation, (b) type of working day, and (c) sector where the student develops his professional activity.

Computer Technology is taught in the first semester of the first Computer Engineering course. It is, therefore, a subject that traditionally has a high number of students (95 in 2019/20, 131 in 2020/21, and 153 in 2021/22) and a good indicator of how the number of enrollments in this degree has increased. The basic objective of this 6-credit European Credit Transfer and Accumulation System (ECTS) course is to give a vision, as complete as possible, of the fundamentals of the structure, organization, and design of computers. Students learn to use the different representations of data at the machine level, know the history of computer architectures, and understand the basic building blocks of computer architectures and their role in them and the basic architecture of Von Neumann. In general, it works on logic and digital systems, the representation of data at the machine level, the organization at the assembler level, the organization and structure of memory. While in a specific way it seeks to delve into the structure, organization, operation, and interconnection of computers.

In the first week of the course, students attend a presentation session where they are asked about their hobbies and previous knowledge through an anonymous survey 
to find out their level of depth in the subject and its special characteristics. As a result of this analysis, on a regular basis, a high number of students (above $95 \%$ on all occasions) state that they like the teacher to relate the theoretical contents of the subject with real examples and prefer practical exercises based on cases real, close to the reality that they will find in their future professional performance. In 2021/22, 85.9\% affirm that they try to be informed of all the news in the computer science sector. However, the majority have never programmed any type of device $(67 \%)$, have basic or no knowledge of electronics (75\%) and robotics (86.9\%) and, although they like video games $(72.8 \%)$, they have never programmed one nor were they interested in its technical development (75\%).

Baccalaureate

- Vocational training - Non-university Bachelor

Grade

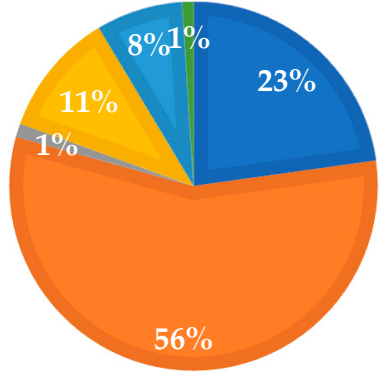

(a)

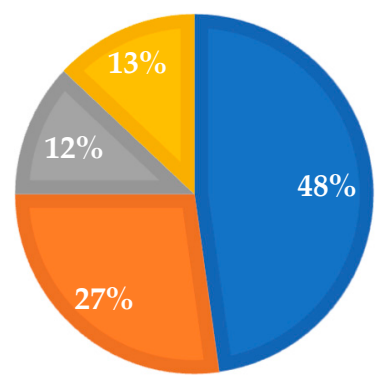

(b)

Figure 5. Distribution of students by educational level. (a) Educational level and (b) number of years the student has not studied before starting the course.

The group of students who are part of the online subject Computer Technology is presented as a large group with heterogeneous profiles at a cultural, generational, and origin level. Therefore, it is necessary to adopt a flexible educational methodology that allows all students to acquire knowledge of the subject through practical examples that motivate and attract them. This work proposal and the teaching case of study lived in its development is presented below.

\section{Proposed Methodology}

This section describes the proposed case of study in Computer Technology, where it is studied how the proposed project contributes qualitatively to the engagement. As a result, the following hypothesis is put forth:

Hypothesis 1. The projects with Arduino in Computer Technology have an impact on the flexibility and personalization of the education.

Hypothesis 2. The projects with Arduino in Computer Technology motivate students and increase their educational productivity. 
Hypothesis 3. The projects with Arduino in Computer Technology affect the quality of education, influencing the learning experience.

To answer the question posed and check whether the proposed hypotheses are met, the case study will be based on analyzing four fundamental parameters: student access to the live platform while the teacher gives the sessions, student participation in the sending of proposals, the marks obtained by the students in their work, and the satisfaction surveys carried out on the students.

\subsection{Organization}

Computer Technology is taught completely online in the Computer Engineering Degree. To take it, students have access to the SAKAI platform, where they can access all course materials, the forum, and virtual face-to-face sessions with the teacher.

The course materials are preloaded on the platform at the beginning of the course and include the subject manual, pre-recorded videos with master lessons, workbooks solved for each topic, additional materials to delve into the main concepts studied, and a schedule detailed planning week by week. Also, it includes access to continuous assessment materials that include two individual activities, a group activity, and a self-correcting test for each topic. Despite being preloaded with these materials, the course is taught synchronously by the teacher, who oversees the attendance and energizes the forum, conducts weekly tutorials, and gives lectures.

The face-to-face sessions of the subject are held live, in a schedule that is adapted weekly to the majority preferences of the students (mostly of European and Latin American origin). The lectures are a total of 20 and are distributed throughout the course and six laboratory sessions of $2 \mathrm{~h}$. Additionally, the contents worked on in these sessions are complemented with two more tools. On the one hand, the forum is used as a tool to expand the work carried out in the face-to-face lectures with current news, debates, and resolution of practical exercises. On the other, the teacher conducts two online weekly tutoring sessions open to all students and without prior appointment that students can use (or not) to resolve all their doubts and raise concerns with the teacher. In these tutorials, students can communicate with the teacher through their webcam and microphone or through a chat.

The forum is configured to show a conversation by topic, one for each activity that students must deliver, one to organize student workgroups, and another to resolve any unrelated questions with the previous items. Additionally, students have hidden forums for the teacher that they can use to contact each other and share information. The teacher has a commitment to reply within a maximum period of $48 \mathrm{~h}$ to the messages. However, as far as possible, the teacher encourages discussion among equals and has a guiding role. From week four of the course, the teacher proposes exercises of similar complexity to the forum that the student can find in the exam, and discussions between students are encouraged until a joint resolution is reached. In these exercises, which present high participation of all the students, the teacher does not confirm the solution until, at least, $10 \%$ of the students have proposed their complete solution or 15 days have elapsed since its publication.

Also, the students have personal tutors who communicate continuously with them. These tutors know their concerns and communicate with the teacher whenever they consider it necessary to help the student and facilitate the work of the teachers.

\subsection{Flexible Proposal Lab}

One of the risks of Computer Technology is the management of the high number of students that the subject has and being able to attend to their individual characteristics to make the teaching-learning process more flexible. Live lectures always bring together at least $65 \%$ of all students. These sessions are recorded and, later, the students can reproduce them as many times as they want. This facilitates the follow-up of those people with incompatible schedules. In the case of having a question, the student can solve it through 
one of the four mechanisms enabled: (i) use of the chat enabled during the master session interacting directly with the teacher during class, (ii) use weekly tutorials with the teacher, (iii) use of the forum, and (iv) contact through the tutors who contact the teacher privately in the case of not wanting to ask openly in public.

In this multicultural and complex educational context, it does not seem logical to propose a single activity closed to all students equally as part of the continuous assessment. For this reason, in this teaching case of study, shown in Figure 6, it was proposed to modify the two individual activities that students must deliver as part of their continuous assessment for project-based learning using Arduino-type hardware devices, which is a low-cost platform of free software more widespread in the world. To do this, students must choose at least two of the four proposed projects:

- Build a binary clock. This challenge includes the hardware development of a real binary clock that marks the exact time in hours, minutes, and seconds through different colored LEDs. Additionally, the system has had improvements, such as the option of alarm or warning of hours through melodies.

- $\quad$ Build an elevator and its associated security systems in a hotel. The challenge describes the constructive characteristics of a hotel and its security needs that must be resolved. Additionally, the system has included improvements, such as music during the journey or light when the elevator door is opened.

- Build an original video game that exercises the memory of users. The challenge presents a series of constructive conditions that the video game must meet, such as the number of inputs and outputs to be configured, the number of Electrically Erasable Programmable Read-Only Memory (EEPROM) to be configured by the student or number of players. Additionally, the student can increase the complexity of the game or include extra gadgets in order to differentiate his proposal from the rest of the classmates.

- Design of an original skill video game using a liquid-crystal display (LCD) screen. This challenge proposes the development of a video game that allows the user to interact with the system through an LCD screen and increases the complexity of the game with the hits it gets. Additionally, the student can make the video game more attractive by including LEDs or music at specific times.

Each project is designed to be developed with physical hardware (devices, such as Arduino or generic board), programming with ArduinoBlocks or Arduino IDE, or through simulation models with Autodesk ${ }^{\circledR}$ TinkerCad ${ }^{\circledR}$. The difficulty depends on this choice, since the proposals to be carried out in simulation are more demanding. Also, Fritzing is used for Printed Circuit Board (PCB) layout design and schematic drawing, as can be seen in Figure 7.

The students have the statements of each challenge at the beginning of the course and it is not necessary to notify the teacher of their choice or preference in advance.

During the course, there are six laboratories of $2 \mathrm{~h}$ and a weekly micro-pill where the minimum basic concepts for facing these projects are explained. Firstly, an initial laboratory (Lab 0) is developed where the basic concepts of Arduino devices are worked (material necessary in the projects and how to find it, basic components, $\mathrm{I} / \mathrm{O}$, system power and installation, and basic concepts of the software). Each of the following labs is focused on explaining how to carry out basic notions common to all projects, both in simulation and using physical hardware. The level of precision and difficulty increases in each session, so it is important that students attend or view all sessions in the order of delivery. Thus, in Lab 1, the numbering systems, digital counters, and how to view the results on the device are explained. In Lab 2, the user-defined functions supported by Arduino platforms and the construction of logic functions are practiced, and in Lab 3, the main I/O and their configuration based on those functions are practiced. Next, the use of memories, specially EEPROM, is taught in Lab 4. Finally, how to work with more complex elements, such as LCD screens, and the development of more complex programs for multitasking is described in Lab 5. During these sessions, the teacher develops small practical examples step-by-step 
that are motivating and directly applicable to the projects, using simulations (Figure 8a) and the Arduino board (Figure 8b). Students can follow these examples from home and ask the teacher any questions that may arise during the course.
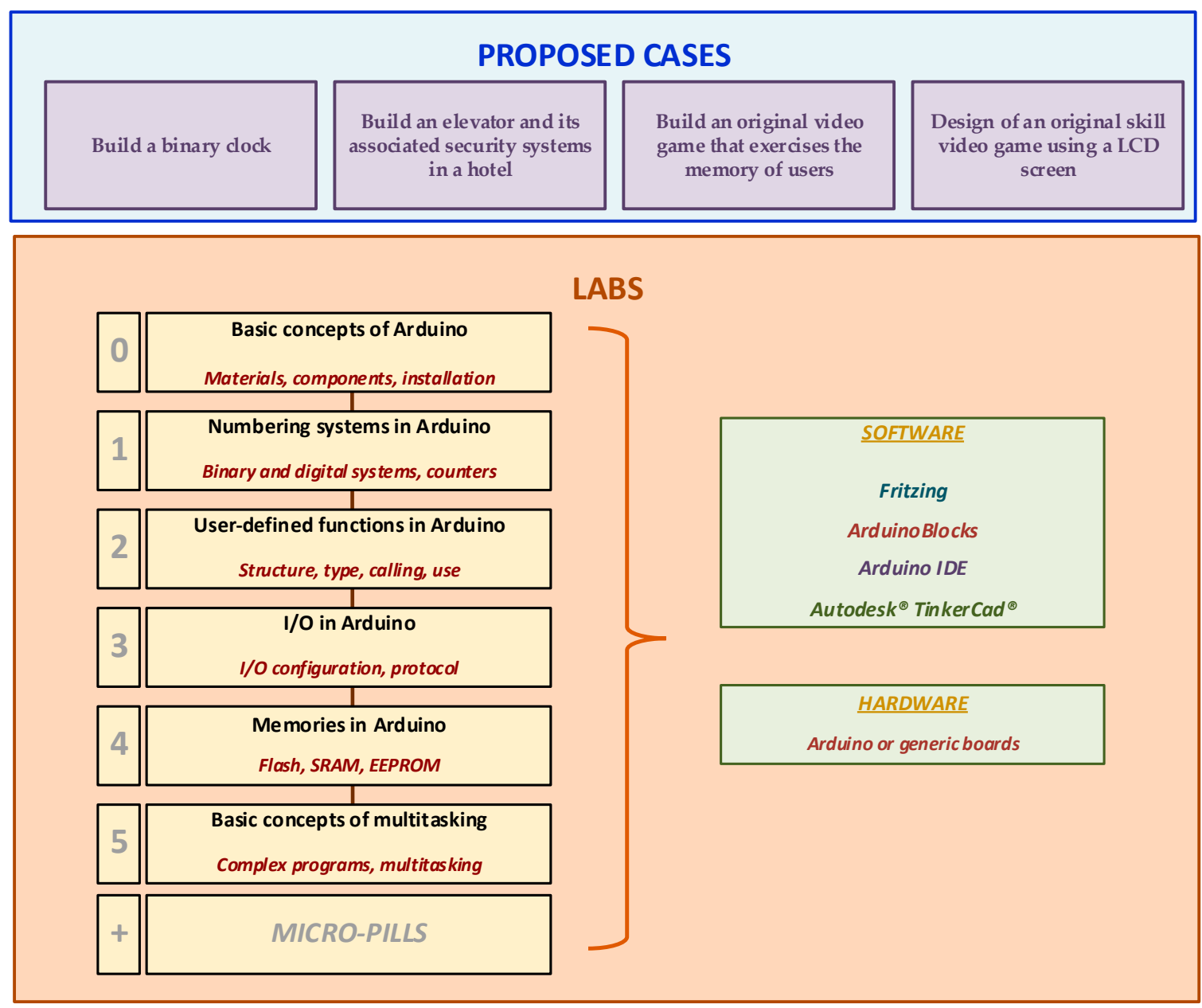

Evaluation + Development of possible examples

Rubrics + Turnitin

Figure 6. Proposed work scheme in the teaching case of study. 


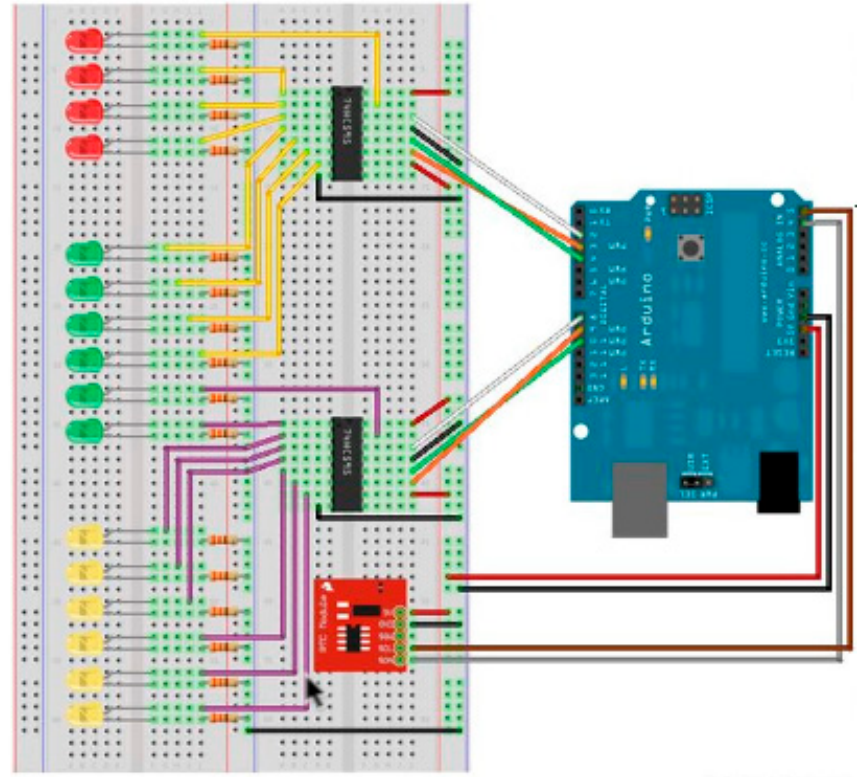

Figure 7. Schematic of the project Build a binary clock proposed by a student using Fritzing.

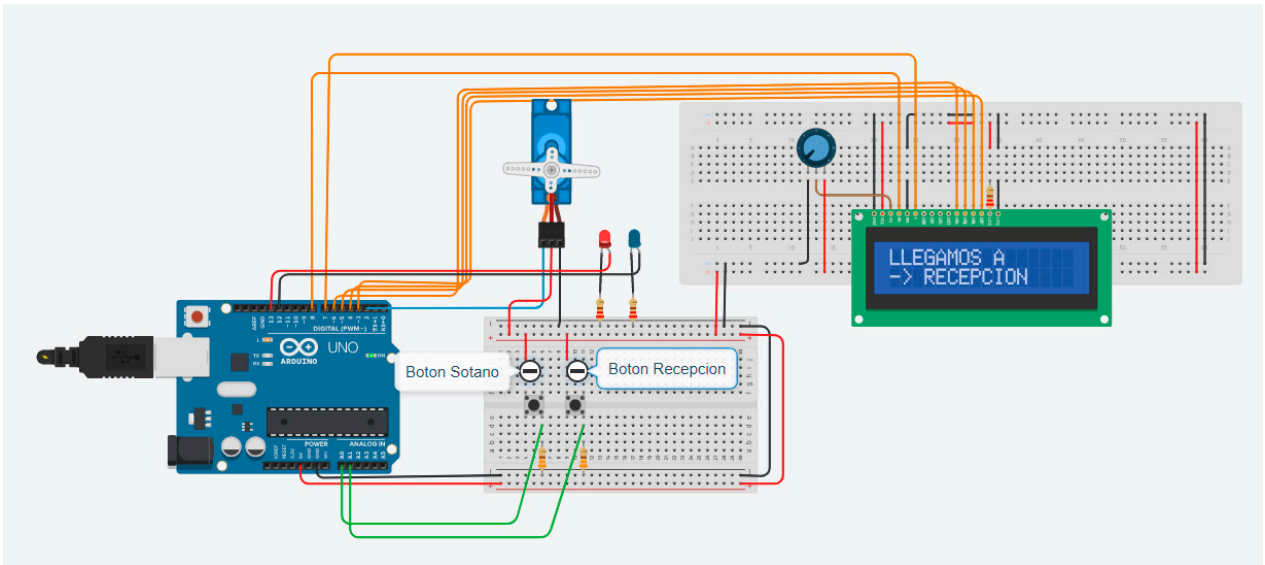

(a)

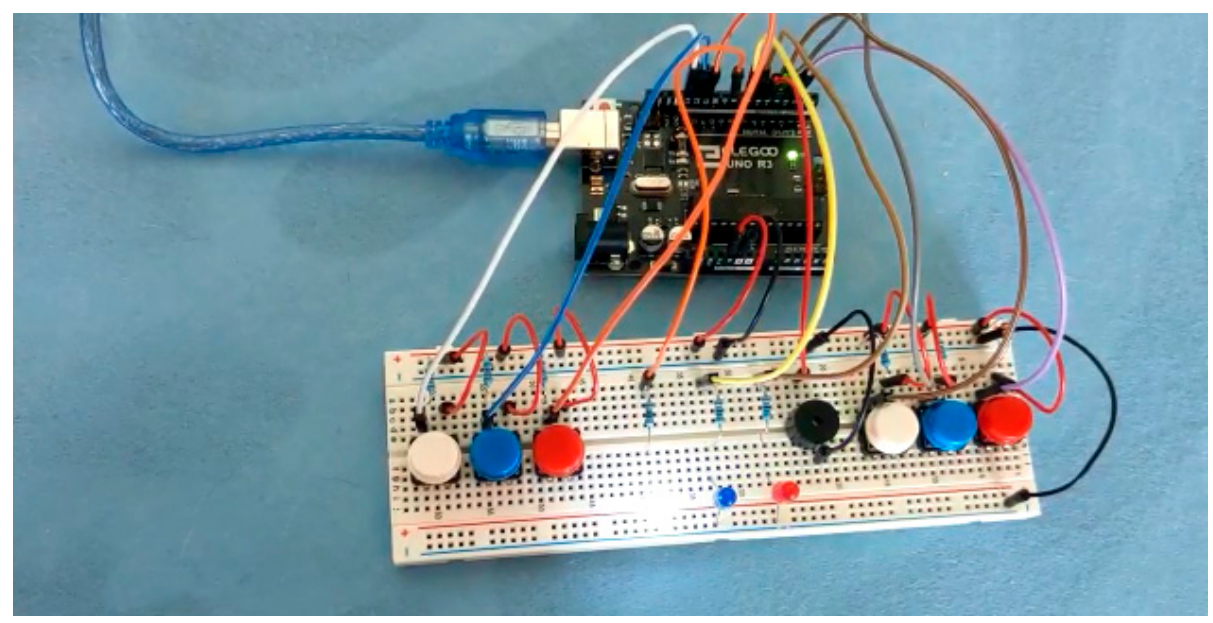

(b)

Figure 8. Examples shown during the development of one of the labs in (a) simulation of the project Build an elevator and its associated security systems in a hotel and (b) Build an original video game that exercises the memory of users with Arduino board. 
Additionally, the student has micro-pills and a manual of basic exercises developed step-by-step that complement the training received in the laboratory. Students can use these to develop their work independently and/or search for ideas to enrich their proposal.

\subsection{Evaluation}

To evaluate the projects, all students must submit a complete report that includes the development of their proposal, the code, and configuration of the hardware used and a video, where they explain and demonstrate the operation of their proposal.

Each project includes its own rubric provided to the student with the statement. As an example, Table 1 includes the rubric for the project Design of an original skill video game using an LCD screen.

Table 1. Rubric of the project Design of an original skill video game using an LCD screen.

\begin{tabular}{|c|c|c|c|}
\hline Criteria & Description & Maximum Score & Weight \\
\hline 1 & The student presents a correct and clear report. & 1 & $10 \%$ \\
\hline 2 & $\begin{array}{l}\text { Verification that the video game works in simulation. The player and } \\
\text { obstacles appear on the screen. The player jumps when the user } \\
\text { presses a button. Obstacles move. If the user fails, the game ends. }\end{array}$ & 4 & $40 \%$ \\
\hline $3 *$ & $\begin{array}{l}\text { When the user starts the game, a welcome message appears and } \\
\text { "GAME OVER" appears when the user fails. }\end{array}$ & 1 & $10 \%$ \\
\hline $4^{*}$ & $\begin{array}{l}\text { A counter counts the number of hits correctly. When the user starts a } \\
\text { game, the counter is reset to } 0 .\end{array}$ & 1 & $10 \%$ \\
\hline $5 *$ & Obstacles move faster when the user hits the mark. & 1 & $10 \%$ \\
\hline $6 *$ & A buzzer sounds when the user jumps and when the game ends. & 1 & $10 \%$ \\
\hline \multirow[t]{2}{*}{$7 *$} & $\begin{array}{l}\text { The student introduces and explains a new improvement in the } \\
\text { proposed video game in simulation and/or shows its real assembly } \\
\text { working in the video. }\end{array}$ & 1 & $10 \%$ \\
\hline & & 10 & $100 \%$ \\
\hline
\end{tabular}

* To add the points obtained in criteria $2-7$, it is necessary to meet the requirements of criteria 1 and 2.

One of the reasons for choosing Arduino was the large amount of material developed and distributed for free. Students have access to millions of examples and step-by-step tutorials on the web with just one click. However, this can also be a disadvantage when presenting projects if they are not very specific because students can find similar proposals on the Internet and deliberately copy them. To avoid this situation, all reports and materials submitted will be analyzed with the plagiarism detection tool, Turnitin, and, in case of detecting a high coincidence with another source, it will be automatically scored with a 0 .

The continuous evaluation of the subject represents $40 \%$ of the mark. The $60 \%$ corresponds to the mark obtained in the exam. Each of these proposed projects represents $45 \%$ of the total value of the continuous assessment mark. If the activity does not reach, at least, a score of 5 out of 10, it will be considered unsuitable and will not score in the continuous evaluation. This prevents students from submitting low-level or poorly elaborate work.

At the end of the labs, the students carry out a satisfaction survey focused on knowing their opinion about the activities and materials, the level of difficulty, their satisfaction with the objectives achieved, and proposals for improvement. The results of this survey, like the results of the initial survey, are shared in the forum to make students participate in the results and show them the interest of the teacher in their opinion. Finally, students attend a master session where the teacher presents different possibilities to solve the projects so that the students analyze the problem from different points of view and enrich their experience. 


\section{Discussion}

Online teaching is currently a challenge for many teachers due to the use of new technologies and methodologies adapted to the needs of the dynamics generated in the classroom [29]. Thinking that this type of teaching can be configured in a fixed way to be consumed by all students equally is a mistake. An in-depth study of the profiles of the students of the Degree of Computer Engineering in recent years, especially influenced by the COVID-19 pandemic, has shown a diverse and very broad context that must be covered. Students are attracted by flexibility, health security, and zero mobility to train and achieve their goals, both vocational and work. For this reason, new student profiles are appearing: a greater number of women, people without work, entrepreneurs and students from other countries, or people who work abroad. Although these students share a classroom, they differ in terms of their economic situation, geographic location, concerns, academic knowledge, and family and work responsibilities.

The teacher cannot turn his back on this reality and must know both their profile and their hobbies, since it is important to personalize the teaching-learning process and adapt it to their needs and concerns to enrich teaching and motivate them to continue with their studies. If this is not done, students run the risk of being demotivated and not continuing with their studies because they feel isolated, have a lack of study habits or links with the university, classmates or content, and a lack of stimuli that encourage them to continue. Along these same lines, the recent literature about education in Science, Technology, Engineering, Art, Mathematics (STEAM) includes other similar studies that also try to respond to these new needs of students in a pandemic environment and adapt the activities of face-to-face learning to teach through remote and hybrid online environments. One of these proposals is [30], a mixed learning reality is proposed that addresses an alternative to the face-to-face engineering laboratory through a platform with access to a remotely controlled and programmed robotic arm. In [31], the authors explore how an association of STEAM university teachers took advantage of digital tools and collaborative pedagogies to teach science, technology, and engineering. While other approaches, easily extended to other academic disciplines, emerge to strengthen the resilience of the educational systems in times of crisis. This occurs in [32], where important attributes, such as adaptability, creativity, connectivity, diversity, and resiliency, are highlighted and integrated into pedagogical components for effective teaching and learning within an online environment.

Another important aspect to consider is the skills that students acquire. Some subjects require virtual laboratories or teaching experiences that allow them to compensate for this issue with tools or physical devices that were traditionally handled in face-to-face laboratories. Online teaching must take care of this aspect to offer students an experience close to reality that they will find in their future professional performance without losing quality in the skills acquired. In this sense, universities have developed different methodologies to meet these needs successfully, through kits sent to students, online laboratories, or blended learning. However, in this work, it is proposed to develop project-based learning where students commit to the project as much as they want or can and develop their skills in simulation and/or real hardware devices of their property.

The success of this academic case of study is estimated through objective data measured on the platform (student access to the live platform while the teacher gives the sessions, student participation in the sending of proposals and the marks obtained by the students), and the satisfaction surveys carried out on students after the case study. On the one hand, Table 2 shows the fundamental parameters obtained from the platform in the last three courses. Student attendance at online life sessions has grown both in average number of students (from $8.42 \%$ in $2019 / 20$ to $59.21 \%$ in $2021 / 22$ ) and in peak values (65.79\% of students attended some sessions compared to $18.32 \%$ in $2020 / 21)$. Although the sessions are recorded and can be viewed at any time during the course, these values show that the students were more interested and motivated to attend the sessions presented in the face-to-face sessions and interact with the teacher live. In addition, the number of students who have delivered the project in $2021 / 22$ is $72.37 \%$, with participation increasing 
significantly compared to previous years. Although the percentage of students presented only represents a difference of 6.78 points compared to the previous year, the number of students is greater due to the increase in students who have experienced the subject. Even the quality of the works has increased because the average marks of the students have increased with respect to previous years, reaching 8.84 out of 10 maximum possible points. To complete the information on this value, Figure 9 shows the distribution of the grades obtained by the students where a greater number of grades lower than 6 can be seen in subsequent years, while in this experience, the highest number of marks obtained are in the range of 9 to 10 points out of $10(67.35 \%)$. The latter denotes that the flexibility and personalization of the proposed projects have an impact on the students, motivating them to successfully complete the proposed activities.

Table 2. Summarize of analyzed parameters of live class attendance, number of students doing the project and their marks.

\begin{tabular}{|c|c|c|c|c|}
\hline & \multicolumn{2}{|c|}{ Live Class Attendance } & \multirow{2}{*}{$\begin{array}{l}\text { Students Who Carry } \\
\text { out the Project }(\%)\end{array}$} & \multirow{2}{*}{$\begin{array}{c}\text { Average Mark } \\
(\text { Maximum Value }=10)\end{array}$} \\
\hline & Average Assist (\%) & Peak Assist (\%) & & \\
\hline $2019 / 20$ & 8.42 & 18.95 & 69.47 & 6.54 \\
\hline $2020 / 21$ & 13.74 & 18.32 & 65.79 & 8.06 \\
\hline $2021 / 22$ & 59.21 & 65.79 & 72.37 & 8.84 \\
\hline
\end{tabular}

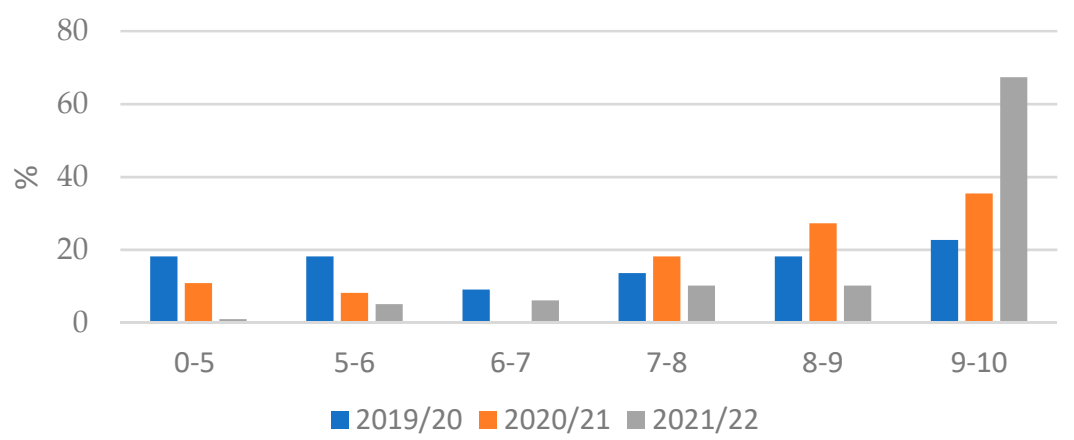

Figure 9. Distribution of the marks obtained by the students in their projects.

On the other hand, the satisfaction of the students is shown in Table 3, where the marks established by the students in the face of the affirmations that are raised are summarized, where 0 is the minimum possible value and represents the absolute rejection of the student and 5 is the maximum value and expresses that the student is in complete agreement. In it, it is observed that the objected results are always found in values above 3.50. The least valued statement is about the complexity found in the work to be done and its easiness to follow because it is the first work with these characteristics that students have had to deal with in the grade and the highest some of them had no prior knowledge of robotics and electronics. This means that the effort required in the subject has been perceived as high for them, although it was foreseeable because it is a subject in the first semester of the first year and the students have not yet fully adapted to this type of dynamics. While the statement that they have identified with the most is the one that relates greater motivation with the possibility of choosing the type of project to develop. 
Table 3. Summary of questions answered by students after the case study.

\begin{tabular}{l}
\hline \multicolumn{1}{c}{ Question } \\
\hline The realization of a Lab 0, where to explain basic concepts before starting the practices, has been useful for me. \\
Being able to choose if I wanted to do the activities through simulations or with physical hardware has motivated me. \\
Being able to choose if you wanted to do the activities through simulations or with physical hardware has been easy. \\
I have found it easy to follow the development of the laboratories and the tasks that were asked to be carried out. \\
The proposed tasks have helped me to better understand the practical concepts worked on in class. \\
I have learned more thanks to the labs. \\
In general, I am satisfied with the work done and what I have learned. \\
\hline
\end{tabular}

When students were asked how they chose their project, $45.5 \%$ affirmed that they chose the project before attending the labs based on their preferences and tastes. While $54.5 \%$ affirmed that they attended the laboratories and, once they were clear about the contents, they chose the project to develop. People who carried out their projects only in simulation assured that they did so because they considered the other options more difficult (20\%); they found this option more interesting compared to the others $(20 \%)$; or they did not want to buy the necessary material to carry out the assembly real $(60 \%)$. While the people who carried out the experimental setup assured that they did so because they already had the material at home $(33.3 \%)$ or they were interested in the subject and wanted to learn more $(66.7 \%)$. Of these, $28 \%$ previously owned part of the material at home and took advantage of it, while $71.4 \%$ had to buy all the material for the first time.

With the data provided in Tables 2 and 3 and Figure 9, the three hypotheses initially raised in this case study are confirmed. Combining the personalization of the projects and the flexibility in customizing, the projects have motivated the students, who have mostly attended the live sessions to interact with the teacher. In addition, a greater number of students have delivered their project obtaining high marks, which confirms that it has had a positive impact on their experience and has increased their productivity and the internalization of concepts worked on in the subject, thus raising the quality of the teaching experience.

The greatest difficulties were detected when it came to familiarizing themselves with the material, both in the I/O configuration and with the development of code used in programming because most of the students were facing this type of project for the first time.

From the point of view of the teachers, the need to connect theoretical concepts with practical and applicable concepts to motivate students has been evidenced. However, given the diverse profile of the students, it is necessary to find a balance between the basic and advanced contents to satisfy the requirements of all of them. Students with advanced knowledge consider that the labs were carried out slowly and were excessively simple. While the inexperienced students required more attention and help to successfully follow the sessions. These latter students are the ones who require the most attention from the teacher. In addition, using Arduino, both in simulation and experimentally, is a positive experience because students may be familiar with it and/or have a lot of additional material on the Internet that they can consult. However, teachers should be cautious when considering work with this hardware because the Arduino community is very extensive and there is a risk that students may plagiarize their work. A high level of customization of the designs and the defense of the project on video is required to avoid this type of problem.

Other authors have published their experiences developing this type of project during the global pandemic, such as [33], where motivation remained very high, without dropouts, and the experience was successfully concluded. Also, in the area of electronics, different experiences have been published related to robotics laboratories [34], circuits with operational amplifiers using interactive environments [35], Internet of things (IoT) [36], and architecture and hardware with Arduino [37,38], like this case of study. Comparing the results obtained in the proposed case study with these others published in the area, equivalent conclusions are observed in all cases. It is found that this type of strategy attracts students to learn about electronics, motivates them, and improves their understanding of 
the concepts worked on. However, although the results obtained are equivalent, it is not possible to make a comparison between them due to the lack of correlation between their own analyzed parameters.

\section{Limitations}

The limitations of the study have been focused mainly on data collection. On the one hand, it has not been possible to conduct surveys of the teachers involved in the experience in such a way that the satisfaction results could be correlated with those obtained from the students. The low number of teachers involved prevents obtaining valid statistical results. On the other hand, although the study includes the analysis of the live attendance of the students to the online sessions. The platform does not allow the quantification of the number of total views of the classes. Sessions are held at a time that is beneficial to as many students as possible. However, it is possible that many of them cannot attend these live sessions due to work problems, family reconciliation, or various other circumstances. Therefore, the real number of total views of the recorded sessions is assumed to be high and would be a more representative parameter when evaluating the experience.

\section{Conclusions and Future Work}

Online teaching has numerous advantages for students, such as flexibility and the possibility of reconciling with other obligations, such as work or family, and its demand has increased significantly in recent years, especially due to the COVID-19 pandemic. Also, accessibility in online models supposes a clear decrease in geographical barriers and, therefore, in the social gap. In this way, universities with an online modality greatly favor student accessibility to the educational environment. This has meant that teachers face high numbers of students in the same classroom with very heterogeneous profiles (cultural, generational, and/or origin). This makes it more necessary than ever to have a flexible design of activities that meets the personal characteristics of each student, in order to guarantee that all students achieve the objectives established and remain motivated. In addition, every university or higher education institution must be responsible for guaranteeing accessible training for the largest possible number of students. The online university must maintain the same guarantees for all students but with different ways of acting. In online education, it is a priority to develop a set of digital tools accessible to all students.

For all these reasons, a flexible academic case study has been presented for the Computer Technology subject of an online Degree of Computer Engineering focused on projectbased learning. In it, four different projects were proposed that the students chose freely and developed in simulation and/or using Arduino-type devices. When this case study was implemented, its impact on engagement was qualitatively evaluated through four parameters: student access to the live platform while the teacher gives the sessions, student participation in the sending of proposals, the grades obtained by the students in their work, and the satisfaction surveys carried out on the students. The results show that students have increased their grades, doing more elaborate and complex work than in previous courses. Therefore, it is considered that they have satisfactorily integrated the knowledge acquired during the subject. Also, after the development of these projects, the students have shown their satisfaction with the result obtained, evaluating the experience positively and ensuring that this type of proposal has not only motivated them in their studies but has also helped them to consolidate the basic concepts work in the subject. Besides this, it has enriched their knowledge with real examples close to their future professional performance. So, an online learning modality, such as the one offered, directly encourages students to have greater satisfaction with accessibility standards and with the ability to be academically successful in these learning modalities. Therefore, in view of all the above, the conclusions drawn have been verified. However, two limitations were highlighted in this work. On the one hand, the technical inability to measure the total number of views of the recorded sessions was detected. On the other hand, the number of teachers did not allow statistical studies to contrast their vision with that of the students. 
In view of the results obtained and the limitations found, the future works that could arise from this experience are three. First, it is proposed to include in future courses a prior period for defining the proposals with the students, which allows the teaching experience to be made more flexible and adapted to their interests. Secondly, a high level of participation was detected in the subject forum in which students interacted with their classmates in search of advice and help. In this sense, it is interesting to propose a scheme to promote the use of forums not only as an element of consultation but also for the expansion and consolidation of knowledge where the teacher assumes the role of guide. Finally, in view of the limitations in obtaining the data, future work to be proposed includes the development of a software tool that allows the platform to quantify the real number of views of the classroom recordings. This would not only allow one to gain objective data but also observe the workflow of the students and act accordingly to reinforce knowledge and/or eliminate superficialities.

Author Contributions: P.L. is the main researcher of the project that finances this case of study, she has overseen designing the proposal and writing the article. M.P. has overseen coordinating and carrying out the activities that have been carried out and developed the contextualization of the state of the art. L.d.-1.-F.-V. has overseen the contextualization and profile of the student. All authors have read and agreed to the published version of the manuscript.

Funding: This research was funded by Universidad Internacional de La Rioja under the project "Laboratorio Hardware: Experiencia práctica y real con Arduino para alumnos de la asignatura Tecnología de Computadores del Grado de Ingeniería Informática". Also, this work is partially funded by the PLeNTaS project, “Proyectos I+D+i 2019”, PID2019-111430RB-I00.

Conflicts of Interest: The authors declare no conflict of interest.

\section{References}

1. Batanero, C.; de-Marcos, L.; Holvikivi, J.; Hilera, J.R.; Otón, S. Effects of New Supportive Technologies for Blind and Deaf Engineering Students in Online Learning. IEEE Trans. Educ. 2019, 62, 270-277. [CrossRef]

2. Coman, C.; Tîru, L.G.; Meseșan-Schmitz, L.; Stanciu, C.; Bularca, M.C. Online Teaching and Learning in Higher Education during the Coronavirus Pandemic: Students' Perspective. Sustainability 2020, 12, 10367. [CrossRef]

3. Nuci, K.P.; Tahir, R.; Wang, A.I.; Imran, A.S. Game-Based Digital Quiz as a Tool for Improving Students' Engagement and Learning in Online Lectures. IEEE Access 2021, 9, 91220-91234. [CrossRef]

4. Muzaffar, A.W.; Tahir, M.; Anwar, M.W.; Chaudry, Q.; Mir, S.R.; Rasheed, Y. A Systematic Review of Online Exams Solutions in E-Learning: Techniques, Tools, and Global Adoption. IEEE Access 2021, 9, 32689-32712. [CrossRef]

5. Almaiah, M.A.; Al Mulhem, A. A Conceptual Framework for Determining the Success Factors of E-Learning System Implementation Using Delphi Technique. J. Theor. Appl. Inf. Technol. 2018, 96, 1-15.

6. Almaiah, M.A.; Al-Khasawneh, A.; Althunibat, A. Exploring the Critical Challenges and Factors Influencing the E-Learning System Usage during COVID-19 Pandemic. Educ. Inf. Technol. 2020, 25, 5261-5280. [CrossRef] [PubMed]

7. Almaiah, M.A.; Al Mulhem, A. Thematic Analysis for Classifying the Main Challenges and Factors Influencing the Successful Implementation of E-Learning System Using NVivo. Int. J. Adv. Trends Comput. Sci. Eng. 2020, 9, 142-152. [CrossRef]

8. Kumar, A.; Krishnamurthi, R.; Bhatia, S.; Kaushik, K.; Ahuja, N.J.; Nayyar, A.; Masud, M. Blended Learning Tools and Practices: A Comprehensive Analysis. IEEE Access 2021, 9, 85151-85197. [CrossRef]

9. Nassr, R.M.; Aborujilah, A.; Aldossary, D.A.; Aldossary, A.A.A. Understanding Education Difficulty During COVID-19 Lockdown: Reports on Malaysian University Students' Experience. IEEE Access 2020, 8, 186939-186950. [CrossRef]

10. Wang, S.; Sun, H.; Wang, F.; Robson, L. Blended Learning: New Prospects for International Higher Education. IEEE Technol. Soc. Mag. 2021, 40, 47-53. [CrossRef]

11. Shoufan, A. Active Distance Learning of Embedded Systems. IEEE Access 2021, 9, 41104-41122. [CrossRef]

12. García-Loro, F.; Baizán, P.; Blázquez-Merino, M.; Plaza, P.; Aroca, A.M.; Orduña, P.; Cristobal, E.S.; Castro, M. Spreading Remote Laboratory Scope Through a Federation of Nodes: VISIR Case. IEEE Rev. Iberoam. Tecnol. Aprendiz. 2019, 14, 107-116. [CrossRef]

13. Villar-Martínez, A.; Rodríguez-Gil, L.; Angulo, I.; Orduña, P.; García-Zubía, J.; López-De-Ipiña, D. Improving the Scalability and Replicability of Embedded Systems Remote Laboratories Through a Cost-Effective Architecture. IEEE Access 2019, 7, 164164-164185. [CrossRef]

14. Kruse, D.; Frerich, S.; Petermann, M.; Ortelt, T.R.; Tekkaya, A.E. Remote Labs in ELLI: Lab Experience for Every Student with Two Different Approaches. In Proceedings of the 2016 IEEE Global Engineering Education Conference (EDUCON), Vienna, Austria, 21-23 April 2016; pp. 469-475.

15. Lee, H. The Rise and Challenges of Post-Pandemic Online Education. IEEE Eng. Manag. Rev. 2021, 49, 54-58. [CrossRef] 
16. Perales, M.; Pedraza, L.; Moreno-Ger, P. Work-In-Progress: Improving Online Higher Education with Virtual and Remote Labs. In Proceedings of the 2019 IEEE Global Engineering Education Conference (EDUCON), Dubai, United Arab Emirates, 8-11 April 2019; pp. 1136-1139.

17. Cordero, A.; Lluch, C.J.; Codesal, E.S.; Torregrosa, J. Towards a Better Learning Models Through OCWs and MOOCs. Int. J. Interact. Multimed. Artif. Intell. 2015, 3, 26-30. [CrossRef]

18. Tobarra, L.; Ros, S.; Hernández, R.; Robles-Gómez, A.; Caminero, A.; Pastor, R. Integration of Multiple Data Sources for Predicting the Engagement of Students in Practical Activities. Int. J. Interact. Multimed. Artif. Intell. 2014, 2, 53-62. [CrossRef]

19. Potkonjak, V.; Gardner, M.; Callaghan, V.; Mattila, P.; Guetl, C.; Petrović, V.M.; Jovanović, K. Virtual Laboratories for Education in Science, Technology, and Engineering: A Review. Comput. Educ. 2016, 95, 309-327. [CrossRef]

20. Culbertson, H.; Kuchenbecker, K.J. Importance of Matching Physical Friction, Hardness, and Texture in Creating Realistic Haptic Virtual Surfaces. IEEE Trans. Haptics 2017, 10, 63-74. [CrossRef]

21. Yang, W.; Yuan, N.; Chinthammit, W.; Kang, B. A Distributed Case- and Project-Based Learning to Design 3D Lab on Electronic Engineering Education. Comput. Appl. Eng. Educ. 2019, 27, 430-451. [CrossRef]

22. Romero-Rodríguez, J.-M.; Aznar-Díaz, I.; Hinojo-Lucena, F.-J.; Gómez-García, G. Mobile Learning in Higher Education: Structural Equation Model for Good Teaching Practices. IEEE Access 2020, 8, 91761-91769. [CrossRef]

23. Delgado, S.; Morán, F.; José, J.C.S.; Burgos, D. Analysis of Students' Behavior Through User Clustering in Online Learning Settings, Based on Self Organizing Maps Neural Networks. IEEE Access 2021, 9, 132592-132608. [CrossRef]

24. Estriegana, R.; Medina-Merodio, J.-A.; Robina-Ramírez, R.; Barchino, R. Analysis of Cooperative Skills Development through Relational Coordination in a Gamified Online Learning Environment. Electronics 2021, 10, 2032. [CrossRef]

25. Tran, T.P.; Meacheam, D. Enhancing Learners' Experience Through Extending Learning Systems. IEEE Trans. Learn. Technol. 2020, 13, 540-551. [CrossRef]

26. Stallings, W. Computer Organization and Architecture; Financial Times Prentice Hall: Hoboken, NJ, USA, 2015; ISBN 978-0-13410161-3.

27. López-Belmonte, J.; Segura-Robles, A.; Moreno-Guerrero, A.-J.; Parra-González, M.-E. Robotics in Education: A Scientific Mapping of the Literature in Web of Science. Electronics 2021, 10, 291. [CrossRef]

28. Mohd-Yasin, F. Effective Strategies for Project-Based Learning of Practical Electronics. Electronics 2021, 10, 2245. [CrossRef]

29. Altalbe, A. Antecedents of Actual Usage of E-Learning System in High Education During COVID-19 Pandemic: Moderation Effect of Instructor Support. IEEE Access 2021, 9, 93119-93136. [CrossRef]

30. Loukatos, D.; Zoulias, E.; Kyrtopoulos, I.-V.; Chondrogiannis, E.; Arvanitis, K.G. A Mixed Reality Approach Enriching the Agricultural Engineering Education Paradigm, against the COVID-19 Constraints. In Proceedings of the 2021 IEEE Global Engineering Education Conference (EDUCON), Vienna, Austria, 21-23 April 2021; pp. 1587-1592.

31. Kier, M.W.; Johnson, L.L. Exploring How Secondary STEM Teachers and Undergraduate Mentors Adapt Digital Technologies to Promote Culturally Relevant Education during COVID-19. Educ. Sci. 2022, 12, 48. [CrossRef]

32. King, I.; Saxena, C.; Pak, C.; Lam, C.; Cai, H. Rethinking Engineering Education: Policy, Pedagogy, and Assessment During Crises. IEEE Signal Process. Mag. 2021, 38, 174-184. [CrossRef]

33. Hernández-Mangas, J.M.; Álvarez, J.A. Project-Based Learning in "Practical Development of Electronic Systems" Course, Weaknesses and Strengths in the Context Imposed by the COVID-19 Disease. IEEE Rev. Iberoam. Tecnol. Aprendiz. 2021, 16, 194-203. [CrossRef]

34. Birk, A.; Simunovic, D. Robotics Labs and Other Hands-On Teaching During COVID-19: Change Is Here to Stay? IEEE Robot. Autom. Mag. 2021, 28, 92-102. [CrossRef]

35. Shehova, D.; Asparuhova, K.; Lyubomirov, S. Study of Electronic Circuits with Operational Amplifiers Using Interactive Environments for Design and Analysis. In Proceedings of the 2021 12th National Conference with International Participation (ELECTRONICA), Sofia, Bulgaria, 27-28 May 2021; pp. 1-4.

36. Sandy, D.; Gary, K.; Sohoni, S. Impact of a Virtualized IoT Environment on Online Students. In Proceedings of the 2020 IEEE Frontiers in Education Conference (FIE), Uppsala, Sweden, 21-24 October 2020; pp. 1-5.

37. Martin, S.; Fernandez-Pacheco, A.; Ruipérez-Valiente, J.A.; Carro, G.; Castro, M. Remote Experimentation Through Arduino-Based Remote Laboratories. IEEE Rev. Iberoam. Tecnol. Aprendiz. 2021, 16, 180-186. [CrossRef]

38. Yang, H.; Hsiao, T.-C.; Zhu, K.; Yang, Y.; Guo, L. An Exploration of Online Teaching Based on Arduino Virtual Simulation Experiments. In Proceedings of the 2021 IEEE 3rd Eurasia Conference on Biomedical Engineering, Healthcare and Sustainability (ECBIOS), Tainan, Taiwan, 28-30 May 2021; pp. 126-128. 